\title{
Complete endoscopic removal of a large appendiceal orifice polyp
}

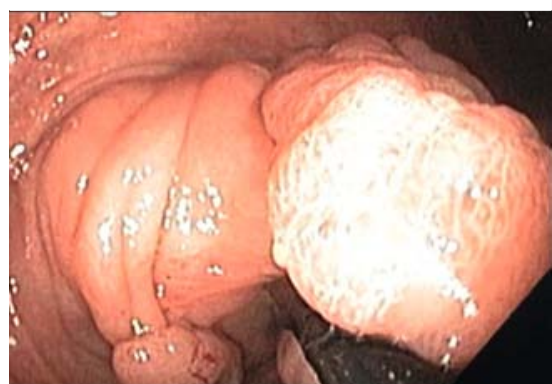

Fig. 1 A 30-mm semipedunculated lesion extending into the appendix, seen at index colonoscopy.

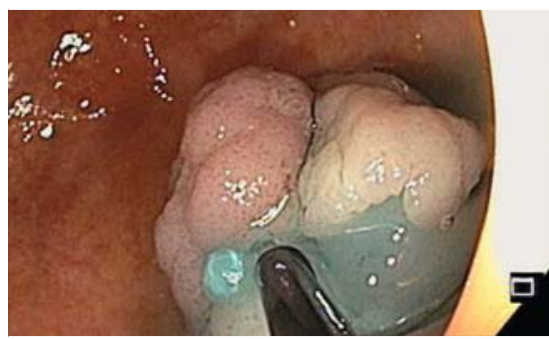

Fig. 2 Adequate lifting of the base of the polyp at the appendiceal orifice was achieved with a mixture of saline, norepinephrine, and methylene blue.

A 51-year-old man was referred to our institution for removal of a large semipedunculated polyp (0-Isp) involving the appendiceal orifice (\$Fig.1). Previous biopsies showed a tubulovillous adenoma (TVA) with high grade dysplasia (HGD). Endoscopic resection under general anesthesia in the operating room was proposed and was agreed to by the patient. A 30-mm 0-Isp lesion extending into the appendix ( $>75 \%$ of orifice) was found, with narrowband imaging showing a regular mucosal pattern without areas suggestive of deep invasion. Different endoscopic resection techniques were discussed at this point, such as endoscopic full-thickness resection (EFTR) and endoscopic submucosal dissection (ESD). However, the size, involvement of the appendiceal orifice, and presence of identifiable margins of the lesion favored

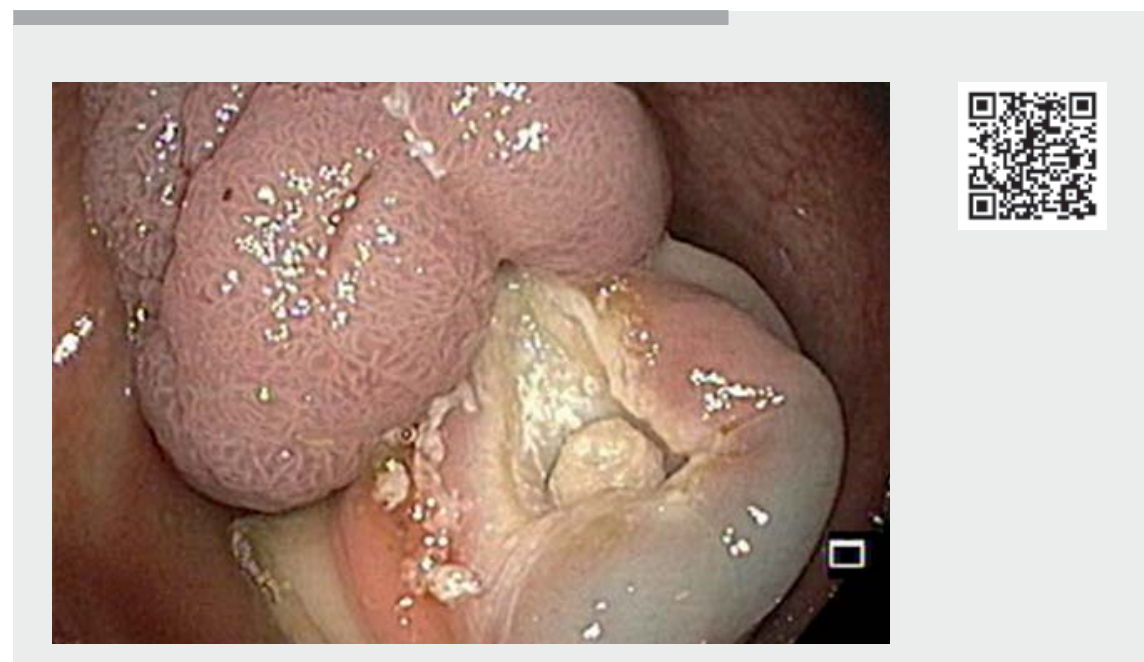

Video 1 Conventional endoscopic mucosal resection using the inject-and-cut technique was performed to resect a large semipedunculated lesion involving the majority of the appendiceal orifice. En bloc resection was achieved without complications.

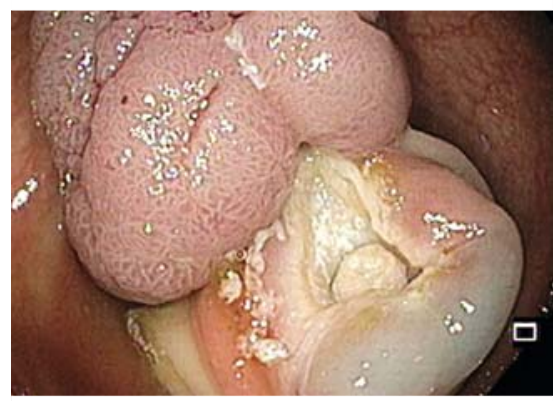

- Fig. 3 Conventional endoscopic mucosal resection using the inject-and-cut technique was attempted and was successful, with complete en bloc snare resection achieved.

conventional endoscopic mucosal resection $(E M R)(\triangleright$ Video 1$)$.

Adequate lifting of the base was achieved with a mixture of saline, epinephrine, and methylene blue (> Fig.2). Conventional EMR using the inject-and-cut technique was successful, with complete en bloc snare resection achieved ( $\mathbf{F i g} . \mathbf{3}$ ). An adjacent small 6-mm sessile polyp was also removed. After a suspected muscular wall injury, the mucosal defect was completely closed with endoscopic clips

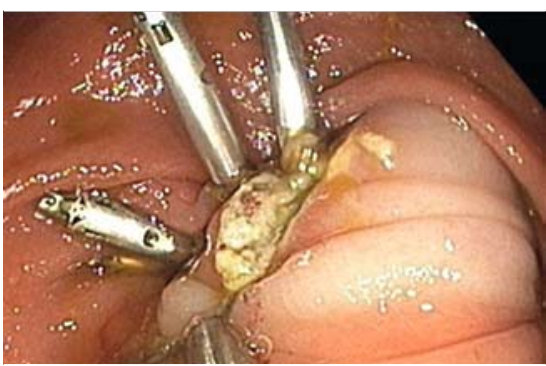

Fig. 4 The mucosal defect was completely closed with endoscopic clips after a suspected muscular wall injury.

( Fig.4). Histopathology revealed a TVA with HGD, measuring $25 \times 20 \times 20 \mathrm{~mm}$, with free margins ( $\mathbf{F i g} \mathbf{5}$ ). The patient was started on prophylactic antibiotics and discharged on day 3, after intraprocedural complications had been excluded.

Endoscopic resection of lesions of the appendiceal orifice is technically challenging, carrying a high risk of complications and incomplete resection. Consequently, these lesions are commonly referred for surgery. Recently, conventional/underwater EMR, ESD, and EFTR 


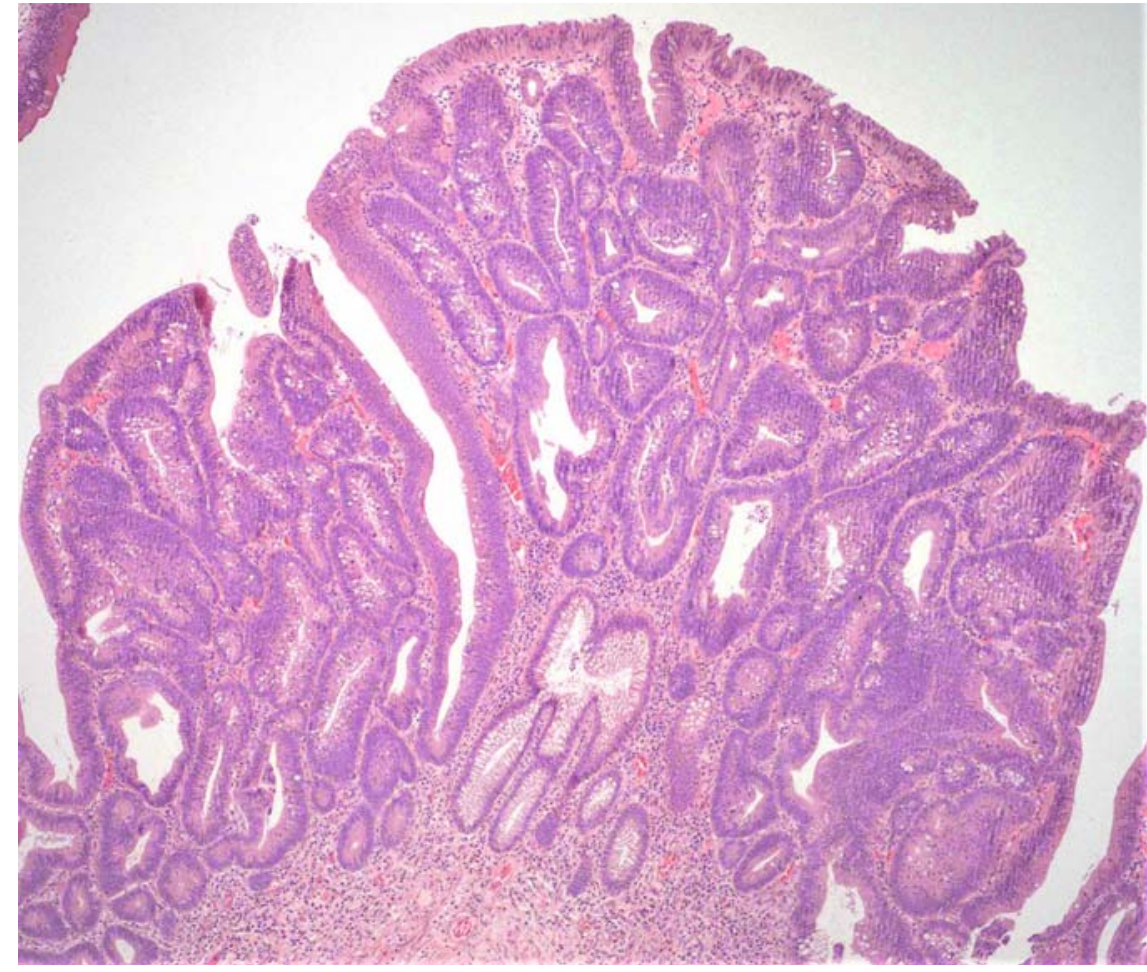

- Fig. 5 Histopathology showed a tubulovillous adenoma with high grade dysplasia (Hematoxylin and eosin). have been described as effective and safe treatment achieving high rates of complete resection $[1,2]$. The choice between them is made according to the size, degree of appendiceal orifice involvement, and characteristics of the lesion [2]. Large lesions involving the appendiceal orifice and identifiable margins are still best approached using EMR techniques which have the advantage of being readily available and inexpensive with few complications. However, lesion size above $20 \mathrm{~mm}$ and involvement of more than $75 \%$ of the appendiceal orifice are risk factors for piecemeal resection, perforation, and recurrence [2].

Endoscopy_UCTN_Code_TTT_1AQ_2AD

\section{Competing interests}

The authors declare that they have no conflict of interest.

The authors

Joana Carvão ${ }^{1,2}$, Diogo Libânio 2,3

Rodríguez-Carrasco ${ }^{2}$, Madalena Souto

Moura $^{4}$, Luís Pedro Afonso ${ }^{4}$, Mário Dinis-

Ribeiro $^{2,3}$

1 Gastroenterology Department, Hospital Central do Funchal, Funchal, Portugal

2 Gastroenterology Department, Portuguese Oncology Institute of Porto, Porto, Portugal

3 MEDCIDS - Department of Community Medicine, Health Information and Decision, Faculty of Medicine, University of Porto, Porto, Portugal

4 Pathology Department, Portuguese Oncology Institute of Porto, Porto, Portugal
Corresponding author

\section{Joana Carvão}

Gastroenterology Department, Hospital Central do Funchal, Avenida Luís de Camões, no 57, 9004-514, Funchal, Madeira Island, Portugal

joanacarvao@hotmail.com

\section{References}

[1] Song EM, Yang H], Lee H] et al. Endoscopic resection of cecal polyps involving the appendiceal orifice: a KASID multicenter study. Dig Dis Sci 2017; 62: 3138-3148

[2] Vargas JI, Teshima CW, Mosko JD. Management of periappendiceal orifice polyps. Clin Gastroenterol Hepatol 2020; 18: 24252429

Bibliography

Endoscopy 2022; 54: E71-E72

DOI 10.1055/a-1374-9793

ISSN 0013-726X

published online 15.3 .2021

(c) 2021. Thieme. All rights reserved. Georg Thieme Verlag KG, Rüdigerstraße 14, 70469 Stuttgart, Germany

\section{ENDOSCOPY E-VIDEOS \\ https://eref.thieme.de/e-videos}

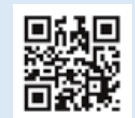

Endoscopy E-Videos is an open access online section, reporting on interesting cases and new techniques in gastroenterological endoscopy. All papers include a high quality video and all contributions are freely accessible online. Processing charges apply (currently EUR 375), discounts and wavers acc. to HINARI are available.

This section has its own submission website at https://mc.manuscriptcentral.com/e-videos 